sionalisation has been all about certification and exclusion. An exam should exist to improve standards, but because it must also acknowledge achievement of a required standard some people must always fail. If everyone passed where would be the point? As the registrar of the Royal College of Physicians says in his speech to new members, "The MRCP is not an easy exam. Nor, now that you have passed it, would you wish it to be."

The question, then, is not whether to examine doctors' competence, but how to. And it is a question that should be openly debated. I have been assured by physicians and surgeons who examine for the membership and fellowship exams that selection and training of examiners is rigorous and that both exams undergo intense internal audit. But secrecy fuels speculation and might even justify cynicism. The confidence with which the RCGP opens its doors to outside scrutiny sends an unmistakable challenge to other colleges to do the same.

\title{
The Royal College of Psychiatrists, 150 years on
}

\author{
Henry Rollin
}

On 27 July the Royal College of Psychiatrists will celebrate its 150 th birthday. With a century and a half under its belt the college can legitimately claim to be the oldest association of psychiatrists in the world.

The original association was the brainchild of Dr Samuel Hitch, resident superintendent of the Gloucestershire General Lunatic Asylum. In a circular letter dated 19 June 1841 and addressed to 83 visiting physicians and resident superintendents of 26 asylums and hospitals in England, seven in Scotland, and 11 in Ireland he suggested that such an association be formed. His opening paragraph is well worth quoting from because in essence the aims and objects of what he proposed are, with some additions and modifications, the same as those of today's college. It reads: "It having been long felt desirable that medical gentlemen connected with lunatic Asylums should be better known to each other. . . shall communicate more freely the results of their individual experience. . . should cooperate in collecting statistical information relating to insanity-and, above all, should assist each other in improving the treatment of the insane...."

Of the gentlemen approached only 47 replied but, of these, 44 were in favour and three against. It was a reasonably encouraging response, sufficient for Hitch to press ahead and to organise a preliminary meeting at his hospital on 27 July 1841 . There it was decided that an association on the lines suggested in Hitch's letter be established and be known as the Association of Medical Officers of Asylums and Hospitals for the Insane.

The fledgling association got off to a pretty poor start. It was described by one of its founder members, Mr John Thurnam, in 1845 as "this little society"-a sad description, but apt. The attendance at irregularly held meetings was meagre; rarely did it reach double figures. But included among those who did attend, or perhaps more exactly, were able to overcome the difficulties so that they could attend, were stalwarts who have become known as heroes of British psychiatry: John Conolly (Hanwell), Samuel Hitch (Gloucester), Samuel Gaskell (Lancaster), John Thurnam (The Retreat, York) and John Bucknill (Exeter). In 1851, however, under the great John Conolly a renaissance took place. A meeting at the Freemasons' Tavern in London drew an attendance of 26 and was followed by an even more successful meeting a year later in Oxford. Since then the sequence of meetings has been unbroken to this day.

Three important and far reaching events occurred in mid-century. Firstly, at the York meeting in 1844 it was decided to publish a journal, although the Asylum Fournal-the forerunner of today's British fournal of Psychiatry-did not appear until November 1853, under the spirited editorship of Dr (later Sir) John

\section{Royal College of} Psychiatrists, 17 Belgrave Square, London SW1X 8PG

Henry R Rollin, FRCPSYCH, Quondam honorary librarian

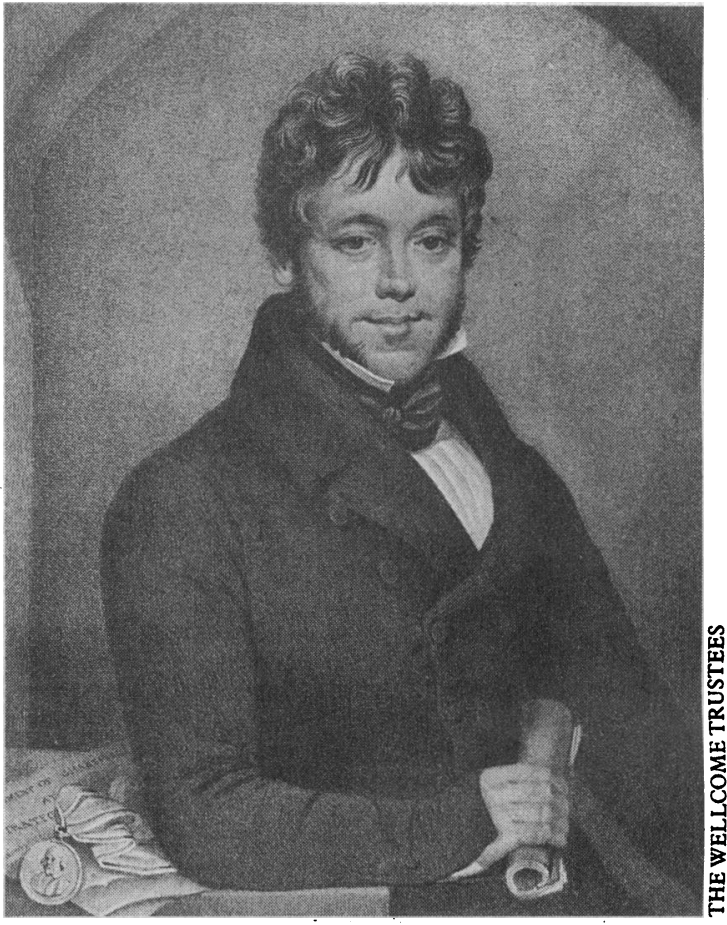

Fohn Connolly, superintendent of Hanwell asylum - one of the heroes of British psychiatry

many members marooned in their institutions the sole means of communication; indeed, the "glue" that bound the association together. Secondly, at the London meeting in 1854 a permanent parliamentary committee was formed, the first positive step designed to influence legislation affecting the control of asylums and the welfare of the patients committed to them. The third event was the institution of the presidency of the college. In 1854 Dr A J Sutherland of St Luke's Hospital, London, was the first to be elected, to be followed by a continuous line of presidents all, without exception, acknowledged leaders of British psychiatry.

With the building of new county asylums under the provisions of the two acts of parliament of 1845 ( 8 and 9 Victoria, $\mathrm{ClO0}$ and C126) the membership of the association rose to 250 in 1864 and to 523 in 1894 . It was decided in 1883-as an index of an increased interest in the affairs of the association and possibly as an attempt at decentralisation-that, in addition to annual meetings, quarterly meetings be held in Scotland and Ireland. These were the forerunners of divisional meetings (the college now has 10 divisions), which have continued to be an important feature of the organisation of the college.

In 1865 , allegedly at the suggestion of Henry 


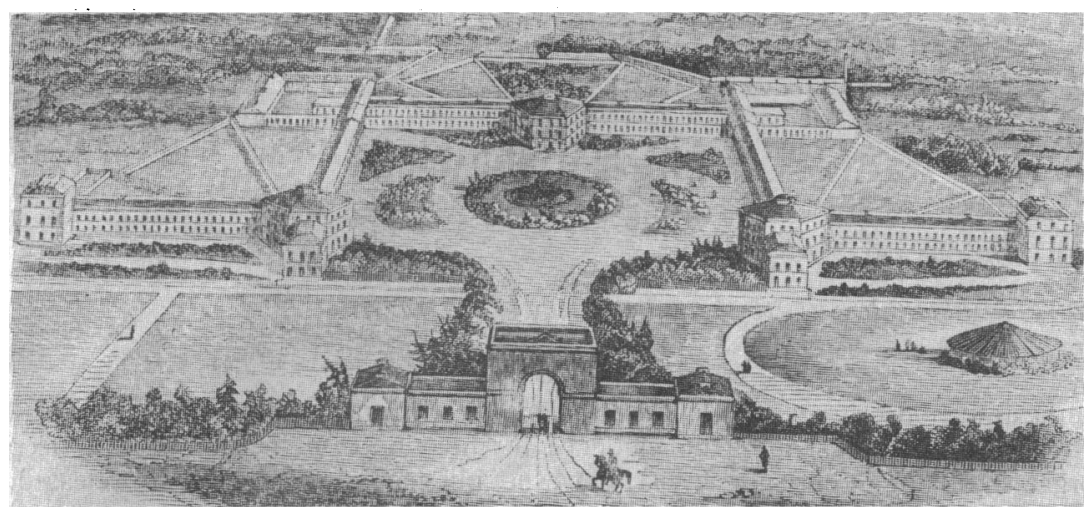

A typical asylum (Hanwell) coronet, the RMPA could exercise far more political clout - as seen, for example, in the vital part it played in the shaping of the Mental Treatment Act 1930 and in the formulation of the 1959 Mental Health Act, the most important charter for the improvement of the lot of the mentally disordered yet devised.

As the self importance of psychiatry - and with it the importance of the RMPA - increased it was felt that it deserved the final accolade, that of translation from an association to a royal college. Eventually, after long years of negotiation with the Privy Council, on 16 June, 1971 the warrant was duly prepared and signed and the Royal College of Psychiatrists came into being. In 1984 His Royal Highness the Prince of Wales graciously consented to become its first patron.

The college is now housed for the first time in premises of its own-at 17 Belgrave Square, SW1, a post-Regency mansion in what is most certainly one of the most elegant quarters of London. In adapting the house for its present needs infinite care was taken to ensure that the decor and furnishings are compatible with its age and dignity.

The membership of the college today exceeds 7000 , all of whom are medically qualified and who are, or aspire to be, specialists in the practice of psychiatry. It has clung to those articles of faith laid down at the time of the inception of the old association in 1841, but with the passage of time it has acquired a host of additional functions and responsibilities. Thus it sets standards of training in psychiatry and holds examinations for entry to its membership; it inspects psychiatric hospitals and promotes medical audit; it publishes its own journal, the British fournal of Psychiatry, now one of the world's most prestigious psychiatric journals; and it represents psychiatry in all its ramifications through the multiplicity of its specialist sections. An ever increasing emphasis is being placed on research, and with this in view a research department has been created within the corpus of the college under the directorship of Professor John Wing.

A 150th birthday merits a very special celebration, and to this end the college has arranged a variety of ambitious activities, including an anniversary ball at the Natural History Museum on 22 October, in the shadow of dinosaurs of even more antique vintage than the college. A more traditional but very appropriate event will be a meeting of the history of psychiatry special interest group in Gloucester-not, alas, in Samuel Hitch's old hospital, which, in pursuance of the government's dubious policy, is now a boarded up shell.

\section{ANY QUESTIONS}

Some patients in their 60s who regularly jog have resting pulses of around 50/minute. Is such a low rate a potential hazard? Are they, for example, more likely to develop heart block?

It is well recognised that athletes performing dynamic exercise commonly have a resting sinus bradycardia. The degree of bradycardia correlates with peak training and is thought to be due largely to increased vagal tone. First degree atrioventricular block is seen in 10-33\% of athletes, but the pulse rate interval returns to normal or shortens after exercise. Second degree atrioventricular block is also more commonly found in athletes. There is no evidence that the slow heart rate or asymptomatic atrioventricular block is of any harm. Rarely, athletes develop symptoms of atrioventricular block, but atrioventricular conduction returns to normal on cessation of training in nearly all cases.

Other causes of a slow heart rate should be considered, particularly if the jogging is only occasional. Apart from drugs and hypothyroidism two common causes are sinus node disease and complete heart block. Examination of the venous pulse may distinguish these, but it is probably wise to perform electrocardiography. If the rhythm is sinus and the patient is asymptomatic no further investigation or treatment is required. If the patient has syncope or presyncope a pacemaker is required. If the electrocardiogram shows complete atrioventricular block a pacemaker is required regardless of symptoms.

In summary, there is no evidence that a slow heart (excluding one caused by complete heart block) in an asymptomatic person does any harm; it does not require any investigation or treatment.-ARIF AHSAN, research fellow, and EDWARD ROWLAND, director, pacing and electrophysiology department, Royal Brompton and National Heart and Lung Hospital, London

Huston TP, Puffer JC, Rodney WM. The athletic heart syndrome. $N$ Englf Med 1985;313:24-9. 